\title{
Coloured dissolved organic matter in aquatic ecosystems of three representative regions of the Arctic according to the data obtained in year 2019
}

\author{
Anastasiia Pashovkina*, and Irina Fedorova \\ Saint Petersburg State University, 7/9 Universitetskaya nab, 199034, St. Petersburg, Russia
}

\begin{abstract}
In this study the laboratory analysis of water samples from three representative regions of the Arctic for content of coloured dissolved organic matter $(\mathrm{CDOM})$ - the important component of natural waters, which has a direct impact on state of aquatic ecosystems, was made. Samples were collected from water objects from the Kola Peninsula, the Yamal Peninsula and the Lena River Delta. The results of the analysis made it possible to determine CDOM concentrations in water. According to the average values, the highest values were obtained for the Yamal Peninsula and lowest - for the Kola Peninsula. The predominance of allochthonous CDOM in the water objects from all three regions was revealed. Moreover, the complete absence of photodegradation processes was determined. For the lakes and rivers from the Kola Peninsula it was also possible to follow seasonal dynamic of CDOM concentration in water and to compare it with earlier obtained data concerning seasonal CDOM dynamic in the Lena River Delta. Results are actual due to the currently existing tendency of climate change which leads to intensification of thermal denudation and thermal erosion processes in the cryolithozone, which are consequently increasing income of allochthonous CDOM in water objects.
\end{abstract}

\section{Introduction}

Vast territories of the Arctic and Subarctic of Russia adjacent to the Arctic Ocean are still relatively little studied in terms of the compound and state of surface waters.

Nowadays, the United Nations Environment Program (UNEP) identifies climate change among the actual environmental problems of the Arctic that entails the intensification of the processes of thermal denudation and thermal erosion in the cryolithozone, which are affecting the water objects located there by increasing the concentration of dissolved organic matter (DOM).

Today, it is known that an excess of DOM in water has a direct impact on the ecological state of aquatic ecosystems. DOM concentration can have a significant effect on biological

\footnotetext{
* Corresponding author: asyapashovkina@gmail.com
} 
activity in them, since coloured dissolved organic matter (CDOM) reduces the intensity of light when it penetrates into the water. Very high concentrations of CDOM can have a restrictive effect on the photosynthesis and inhibit the growth of phytoplankton [1], which forms the basis of aquatic food chains and is the main source of atmospheric oxygen.

To sum up, the increase of CDOM concentrations causes the changes in the ecological status of aquatic ecosystems, which justifies the necessity of CDOM monitoring organization and actuality of this topic. Therefore, the goal of the work is to provide the CDOM parameters in the Arctic aquatic ecosystems and the spatial and temporal features of its dynamic in year 2019. The objectives of the work include: 1) assessment of CDOM parameters; 2) comparison between the results from all three regions in order to find spatial CDOM distribution; 3) consideration of CDOM seasonal dynamics for the water objects from the Kola Peninsula with usage of previously obtained data [2]; 4) the interpretation of the results.

Aquatic ecosystems of three regions: the Yamal Peninsula, the Lena River Delta and the Kola Peninsula, were chosen as the objects of the study.

\section{Methodology of sampling and samples processing}

In total there were 63 samples collected and processed in year 2019: 36 - from the Yamal Peninsula, 14 - from the Kola Peninsula, 13 - from the Lena River Delta.

All samples were filtered using Whatman GF / F glass fibber filters, the pore size of which is $0,7 \mu \mathrm{m}$, and then were stored in cold and dark conditions in order to avoid photodegradation[3].

The filtrated samples were processed in the Otto Schmidt Laboratory in the Arctic and Antarctic Research Institute (AARI) using a dual-beam spectrophotometer SPECORD-200 (Jena Analytic (C), Jena, Germany). For the analysis the range of wavelengths 200-750 nm the ultraviolet and visible parts of the electromagnetic spectrum, which allowed determining the absorption spectra in each sample, was indicated. While analyzing, the optical resolution of the instrument was $1 \mathrm{~nm}$.

During the analysis, the instrument detector measures the intensity of light that has passed through the cuvette with a sample of water in relative to the initial intensity. The transmission of the sample and the reference are calculated by the following equation:

$$
T(\lambda)=I / I_{0}
$$

where $I$ is the light intensity after passing through the cuvettes, $I_{0}$ - the lamp spectrum.

In order to obtain optical density values, the absorption $\left(A_{0}\right)$ of waves by organic matter is investigated:

$$
A_{0}(\lambda)=-\log \left(I / I_{0}\right)
$$

For transformation this value into absorption per meter it is necessary to recalculate the obtained value with reduction to the natural logarithm and taking into account the length of the cuvette $(l)$ in meters using the formula:

$$
\alpha \operatorname{CDOM}(\lambda)=2,303 \cdot A_{0} / l
$$

In this work were used two 0,05 m length quartz cuvettes - one was filled with the water sample and another one was filled with purified water as a blank reference for water without CDOM.

The parameter of optical density $\alpha \mathrm{CDOM}(\lambda)$ directly characterizes the concentration of CDOM. It was estimated at the wavelength of $440 \mathrm{~nm}$, since, according to literature data 
[4], the usage of this wavelength gives the most representative values. While processing the absorption spectra of CDOM, the slope of the CDOM absorption curve was also calculated, its value was determined between 350 and $500 \mathrm{~nm}$ wavelengths.

Calculations were made according to the formula:

$$
a_{C D O M}(\lambda)=a_{C D O M}\left(\lambda_{0}\right) \mathrm{e}^{-S(\lambda-\lambda)}
$$

where $\lambda_{0}$ - wavelength $440 \mathrm{~nm}, \lambda$ - wavelength at the boundary of the considered range.

It has been established [5] that with an increase of the wavelength $\alpha \mathrm{CDOM}$ decreases exponentially.

In addition, there was calculated the parameter $S r$ - the slope coefficient of the spectral curve. It was calculated using the formula:

$$
S r=S(275-295) / S(350-400)
$$

where $S(275-295)$ - spectral angle of inclination in the ultraviolet range (wavelengths from 275 to $295 \mathrm{~nm}), S(350-400)$ - spectral angle of inclination in the visible range (wavelengths from 350 to $440 \mathrm{~nm}$ ).

\section{CDOM parameters}

In this work three measurable parameters of CDOM were used:

1. $\alpha \operatorname{CDOM}(\lambda), \mathrm{m}^{-1}-$ the value of absorption (optical density) of electromagnetic radiation in a certain part of the spectrum (wavelength, $\lambda$ ). Absorption of CDOM on a particular $\lambda$ is directly proportional to the concentration of CDOM in water.

2. The spectral slope $S\left(\mathrm{~nm}^{-1}\right)$ in the ultraviolet (UV) and visible wavelength ranges could be used to determine the type of CDOM in water. $\mathrm{S}$ in visible range with values from 0,014 to $0,017 \mathrm{~nm}^{-1}$ is typical for CDOM in freshwaters $[6,7]$. The values of $\mathrm{S}$ (visible) in the wavelength range from 300 to $500 \mathrm{~nm}$ or from 350 to $400 \mathrm{~nm}$ above $0,02 \mathrm{~nm}^{-1}$ indicate the predominance of autochthonous dissolved organic matter.

3. $\mathrm{Sr}$ - the ratio $\mathrm{S}$ (UV) / $\mathrm{S}$ (visible) can be used as an indicator of photodegradation. $\mathrm{Sr}$ $=1,2$ is a typical $\mathrm{Sr}$ value for the surface fresh water; $\mathrm{Sr}<1,2$ indicates fresh and rich in humic acids terrestrial organic matter; $\mathrm{Sr}>1,2$ may indicate photodegradation [4].

\section{Comparison of CDOM parameters for three considered regions}

The results of the determination of the parameters of CDOM for the three considered regions are presented in Table 1.

Table 1. Summary table of the maximum ( $\max$ ), minimum ( $\min$ ) and average (av) values of CDOM parameters $\alpha \mathrm{CDOM}(440), \mathrm{S}$ (300-500), slope coefficient (Sr) and slope coefficient types for the

\begin{tabular}{|c|c|c|c|c|c|c|c|c|c|c|}
\hline \multirow{2}{*}{ Region } & \multicolumn{3}{|c|}{$\alpha \operatorname{CDOM}(440), \mathrm{m}^{-1}$} & \multicolumn{3}{|c|}{$\mathrm{S}(300-500), \mathrm{nm}^{-1}$} & \multicolumn{3}{|c|}{$\begin{array}{l}\mathrm{Sr}[\mathrm{S}(\mathrm{UV}) / \mathrm{S} \\
\text { (visible)] }\end{array}$} & \multirow{2}{*}{$\mathrm{Sr}$} \\
\hline & $\max$ & $\min$ & av & $\max$ & $\min$ & av & $\max$ & $\min$ & av & \\
\hline $\begin{array}{c}\text { the Kola } \\
\text { Peninsula,June } 2019\end{array}$ & 12,34 & 0,08 & 2,46 & 0,016 & 0,010 & 0,014 & 1,4 & 0,6 & 0,9 & $<1,2$ \\
\hline $\begin{array}{c}\text { the Lena River Delta, } \\
\text { April } 2019\end{array}$ & 8,46 & 0,41 & 3,12 & 0,018 & 0,007 & 0,015 & 1,5 & 0,8 & 1,0 & $<1,2$ \\
\hline $\begin{array}{c}\text { the Yamal Peninsula, } \\
\text { July } 2019\end{array}$ & 19,94 & 0,21 & 5,35 & 0,017 & 0,006 & 0,014 & 2,2 & 0,2 & 0,9 & $<1,2$ \\
\hline
\end{tabular}
Arctic aquatic ecosystems of the Kola Peninsula, the Yamal Peninsula and the Lena River Delta. 
Considering the average values of the absorption of $\alpha \operatorname{CDOM}(440)$, it can be seen that minimum value of $\alpha \operatorname{CDOM}(440)=2,46 \mathrm{~m}^{-1}$ is determined for the Kola Peninsula, which is about two times lower than maximum $\alpha \operatorname{CDOM}(440)=5,35 \mathrm{~m}^{-1}$ determined for the Yamal Peninsula. $\alpha \operatorname{CDOM}(440)$ for the water objects of the Lena River Delta has a middle position and a value of $3,12 \mathrm{~m}^{-1}$. The average slope of the spectral curve is nearly the same in all three regions: it is $0,014 \mathrm{~nm}^{-1}$ for both the Kola Peninsula and the Yamal Peninsula and $0,015 \mathrm{~nm}^{-1}$ for the Lena River Delta. All this values of $\mathrm{S}$ are less than $0,02 \mathrm{~nm}^{-1}$ which indicates the predominance of allochthonous CDOM. According to the Sr, all considered regions have nearly the same average values: 0,9 - the Kola Peninsula and the Yamal Peninsula; 1,0 - the Lena River Delta. These figures are $<1,2$ and mean that, in average, processes of photodegradation are absent.

Moreover, in order to follow the seasonal dynamic of CDOM concentrations for the Kola Peninsula was made the comparison between data for the ice cover period [2] and new date for the open water period (Table 2).

Table 2. Maximum (max), minimum (min) and average (av) $\alpha \operatorname{CDOM}(440)$ for the aquatic ecosystems of the Kola Peninsula for the period of ice cover and for the period of free water surface.

\begin{tabular}{|c|c|c|c|}
\hline \multirow{2}{*}{ Period } & \multicolumn{3}{|c|}{$\alpha \mathrm{CDOM}(440), \mathrm{m}^{-1}$} \\
\cline { 2 - 4 } & $\max$ & $\min$ & av \\
\hline ice cover & 11,29 & 0,19 & 5,74 \\
\hline open water surface & 12,34 & 0,08 & 2,46 \\
\hline
\end{tabular}

According to the average values of the $\alpha \operatorname{CDOM}(440)$ parameter, it can be seen that it is higher in the period of ice cover. However, judging by the maximum values obtained for individual lakes, it is clear that during the open water period they are higher than the winter.

\section{Conclusion}

According to the average values, $\alpha \operatorname{CDOM}(440)$ concentration in the aquatic ecosystems is the lowest for the Kola Peninsula and highest for the Yamal Peninsula. It could be explained by the influence of local factors. The samples from the Kola Peninsula and the Yamal Peninsula were collected during the period of steadily positive air temperatures, when water objects are in conditions of intensification of the processes of thermal denudation and thermal erosion, and allochthonous CDOM is actively coming into them along with runoff from the catchment area. However, the average concentration of CDOM in water is higher for the Yamal Peninsula. It can be connected with the fact that samples were taken from the water objects affected by the inflow from swamps, which is reach in humic and fulvic acids - main CDOM components (swamps occupy $\sim 30 \%$ of the Yamal peninsula).

Another important point here is, also, that in this year the predominance of allochthonous CDOM and absence of photodegradation processes are determined.

For the Kola Peninsula average CDOM concentration in water is higher for the ice period. This happens due to the fact that at this time the lakes are switching to the groundwater feed. The concentration of dissolved organics can be positively affected by groundwater inflow in terrestrial lakes [8]. In addition, the growth of CDOM concentration at this period can be positively affected by decreasing in the activity of the aquatic biota vital processes. Therefore, it can show high values. At the same time the lowest value are typical for the summer-autumn period because of the negative impact of biological factor on CDOM concentration at this time. However, according the maximum values, which are obtained for some particular water objects, CDOM amount is higher for the period of open 
water. This may be connected with the fact that this water objects are located closely to the swamps and, in summer, can receive a runoff saturated with coloured dissolved organic matter from them, as it happen in case of the Yamal Peninsula lakes and rivers. It is important that this seasonal dynamic is similar to one previously obtained for the Lena River Delta [2] and supporting the idea that such seasonal dynamic of CDOM may have a general scheme for all the Arctic aquatic ecosystems. Nevertheless, this idea still needs further investigation support.

To sum up, it is important to mention that data from CDOM samples can be used together with remote sensing data [9] to find the CDOM parameters for larger amount of aquatic ecosystems in order to know more about their properties. This fact can be very useful to the organization of CDOM concentration monitoring system for the Arctic aquatic ecosystems in the future.

The authors thank the Otto Schmidt Laboratory (OSL) of Arctic and Antarctic Research Institute (AARI), which provided the possibility to use laboratory equipment for providing water samples analyses for CDOM.

The work was supported by RFBR 18-05-60291 "Adaptation of the Arctic limnosystems to the climate change".

\section{References}

1. C.A. Stedmon, S. Markager, H. Kaas. Estuar. Coast. Shelf Sci. 51, 267 - 278 (2000)

2. I.V.Fedorova, E.N.Shestakova, A.V.Guzeva, N.Yu. Bobrov, A.A. Pashovkina, Yu. Dvornikov,N. Alekseeva. $A G U$ (to be published)

3. A. Bricaud, A. Morel, L. Prieur. Limnol. Oceanogr. 26, 43-53 (1981)

4. T.V. Skorospekhova, B.Heim, A.A.Chetverova, I.V. Fedorova, N.G. Alekseeva, O. Bobrova,Y.A. Dvornikov, A. Eulenburg, S. Roessler, A. Morgenstern. Polarforschung. 87(2), 125-133 (2018)

5. N.G. Jerlov. Optical oceanography.194 (1968)

6. J.R. Helms, A. Stubbins, J.D. Ritchie, E.C. Minor, D.J. Kieber, K. Mopper. Limnol. Oceanogr. 53(3), 955-969 (2008)

7. M.S.Twardowski, P.L. Donaghay. Journal of Geophys. Res.106, 2545-2560 (2001)

8. J.R.Webb, I.R. Santos, D.T. Maher, D.R. Tait, T. Cyronak, M. Sadat-Noori, et al. Limnol. Oceanogr.64(1), 182-196 (2019)

9. T. Kutser, D.C. Pierson, L. Tranvik, A. Reinart, S. Sobek, K. Kallio. Ecosystems, 8, 709-720 (2005) 